Buletin Ilmiah Math. Stat. dan Terapannya (Bimaster)

Volume 08, No. 3 (2019), hal 453 - 462.

\title{
ANALISIS PERINGKAT WEBSITE PERGURUAN TINGGI NEGERI DI KALIMANTAN DENGAN METODE VIKOR
}

\author{
Malik Abdul Rasyid, Evy Sulistianingsih, Nurfitri Imro'ah
}

\begin{abstract}
INTISARI
Multiple Criteria Decision Making (MCDM) adalah suatu metode pengambilan keputusan untuk menetapkan alternatif terbaik dari sejumlah alternatif berdasarkan beberapa kriteria tertentu. Salah satu metode pengambilan keputusan dalam MCDM adalah metode VIsekriterijumska Optimizacija I Kompromisno Resenje (VIKOR). Metode VIKOR adalah sebuah metode untuk menentukan ranking dari sampel-sampel yang ada dengan melihat hasil dari nilai utilitas, regrets dan jarak solution sebagai alternatif terbaik dari setiap sampel. Tujuan penelitian ini adalah untuk menganalisis peringkat website Perguruan Tinggi Negeri di Kalimantan dengan metode VIKOR. Pengumpulan data menggunakan search engine Google, dengan objek penelitian sebanyak 21 Perguruan Tinggi Negeri di Kalimantan. Berdasarkan hasil penelitian dan pembahasan maka ditarik kesimpulan bahwa Universitas Mulawarman merupakan Perguruan Tinggi Negeri dengan website terbaik di Kalimantan. Peringkat kedua didapat Universitas Tanjungpura, disusul peringkat ketiga dengan Universitas Palangka Raya.
\end{abstract}

Kata Kunci: website, perguruan tinggi, MCDM, VIKOR.

\section{PENDAHULUAN}

Perguruan tinggi merupakan satuan penyelenggara pendidikan tinggi sebagai tingkat lanjut dari jenjang pendidikan menengah di jalur pendidikan formal. Perguruan tinggi di Indonesia saat ini banyak menggunakan website sebagai media publikasi seperti memberikan informasi mengenai profil dan sejarah perguruan tinggi tersebut, serta dapat menginformasikan prestasi-prestasi yang telah diraih. Peningkatan jumlah perguruan tinggi yang memiliki website menyebabkan munculnya berbagai organisasi yang mengeluarkan peringkat website.

MCDM adalah suatu metode pengambilan keputusan untuk menetapkan alternatif terbaik dari sejumlah alternatif berdasarkan beberapa kriteria tertentu. Metode-metode yang ada di MCDM, antara lain: Simple Addaptive Weighting (SAW), Weighted Product (WP), Analitical Hierarki Process (AHP), Technique for Order Preference by Similarity to Ideal Solution (TOPSIS), VIsekriterijumska Optimizacija I Kompromisno Resenje (VIKOR) [1].

Metode VIKOR adalah metode optimasi multikriteria yang digunakan dalam sistem yang kompleks. Metode ini berfokus pada perangkingan dan memilih dari satu set alternatif, dan menentukan solusi kompromi untuk masalah kriteria yang bertentangan, yang dapat membantu para pengambil keputusan untuk mencapai keputusan akhir [2].

Tujuan penelitian ini adalah untuk menganalisis peringkat website Perguruan Tinggi Negeri di Kalimantan dengan metode VIKOR. Batasan masalah dalam penelitian ini adalah data yang digunakan yaitu 21 website Perguruan Tinggi Negeri di Kalimantan, kriteria yang digunakan dalam penelitian ini adalah visibility, size, rich files, dan scholar. Jumlah bobot yang digunakan pada masing-masing kriteria diperoleh dari Webometrics, yaitu visibility sebesar 50\%, size sebesar 5\%, rich files sebesar $35 \%$, dan scholar sebesar $10 \%$. Pengumpulan data untuk masing-masing kriteria menggunakan bantuan search engine Google dan Google Scholar. Data yang digunakan diperoleh dari www.forlap.ristekdikti.go.id yaitu sebanyak 21 website Perguruan Tinggi Negeri yang ada di Kalimantan. Pengumpulan data dilakukan pada hari Jum'at tanggal 1 Februari 2019. 


\section{MULTIPLE CRITERIA DECISION MAKING (MCDM)}

MCDM adalah suatu metode pengambilan keputusan untuk menetapkan alternatif terbaik dari sejumlah alternatif berdasarkan beberapa kriteria tertentu. Kriteria biasanya berupa ukuran-ukuran atau aturan-aturan atau standar yang digunakan dalam pengambilan keputusan. Secara umum dikatakan bahwa MCDM menyeleksi alternatif terbaik dari sejumlah alternatif [3]. MCDM merupakan salah satu metode yang paling banyak digunakan dalam area pengambilan keputusan. Tujuan dari MCDM adalah memilih alternatif terbaik dari beberapa alternatif eksklusif yang saling menguntungkan atas dasar performansi umum dalam bermacam kriteria (atau atribut) yang ditentukan oleh pengambil keputusan. Metode yang didasarkan pada pengukuran kuantitatif yang termasuk MCDM diantaranya: TOPSIS, Simple Additive Weighting (SAW), Linear Programming Techniques for Multidimensional (LINMAP), Analysis of Preference, Complex Proportional Assessment (COPRAS), COPRAS-G, dan Additive Ratio Assessment (ARAS), VIsekriterijumska Optimizacija I Kompromisno Resenje (VIKOR) [1].

\section{METODE VISEKRITERIJUMSKA OPTIMIZACIJA I KOMPROMISNO RESENJE (VIKOR)}

Metode VIKOR adalah sebuah metode untuk optimisasi/optimalisasi kriteria majemuk dalam suatu sistem yang kompleks. Metode ini mengambil keputusan dengan solusi mendekati ideal dan setiap alternatif dievaluasi berdasarkan semua kriteria yang telah ditetapkan. VIKOR melakukan perangkingan terhadap alternatif dan menentukan solusi yang mendekati solusi kompromi ideal. Metode VIKOR sangat berguna pada situasi dimana pengambil keputusan tidak memiliki kemampuan untuk menentukan

pilihan pada saat desain sebuah sistem dimulai [4]. Langkah-langkah yang digunakan dalam Metode VIKOR adalah sebagai berikut [5]:

a. Membuat Matriks Keputusan $(F)$ dengan Persamaan 1 berikut ini:

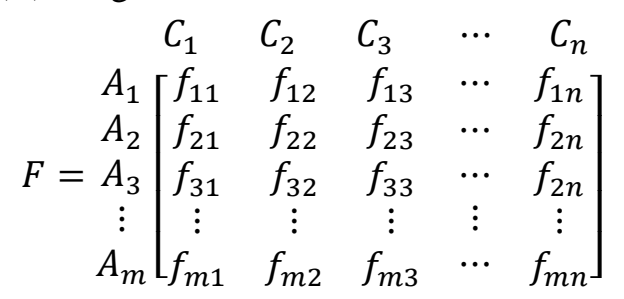

dimana, $A_{i}$ menyatakan alternatif ke- $i$ dengan $i=1,2,3, \ldots, m ; C_{j}$ menyatakan kriteria ke- $j$ dengan $j=1,2,3, \ldots, n$ dan $f_{i j}$ adalah respon alternatif $i$ pada kriteria $j$.

b. Menentukan Bobot Kriteria $(W)$ dengan Persamaan 2 berikut ini:

$$
\sum_{j=1}^{n} W_{j}=1
$$

dimana, $W_{j}$ adalah bobot kriteria $j$ dengan $j: 1,2,3, \ldots, n$.

c. Menghitung nilai terbaik dan terburuk sebagai solusi ideal dinyatakan pada Persamaan 3 dan 4 berikut ini:

$$
\begin{aligned}
& f_{j}^{+}=\max \left\{f_{1 j}, f_{2 j}, f_{3 j}, \ldots, f_{m j}\right\} \\
& f_{j}^{-}=\min \left\{f_{1 j}, f_{2 j}, f_{3 j}, \ldots, f_{m j}\right\}
\end{aligned}
$$

dimana, $f_{j}^{+}$adalah nilai terbaik dalam suatu kriteria $j$ dan $f_{j}^{-}$adalah nilai terburuk dalam suatu kriteria $j$. 
d. Membuat matriks normalisasi dengan menentukan nilai positif dan nilai negatif sebagai solusi ideal dari setiap kriteria. Matriks Normalisasi $(N)$ dengan Persamaan 5 berikut ini:

$$
N_{i j}=\left(\frac{f_{j}^{+}-f_{i j}}{f_{j}^{+}-f_{j}^{-}}\right)
$$

dimana, $f_{i j}$ adalah respon alternatif $i$ pada kriteria $j, f_{j}^{+}$adalah nilai terbaik dalam suatu kriteria $j$ dan $f_{j}^{-}$adalah nilai terburuk dalam suatu kriteria $j$.

e. Menentukan nilai terbobot dari data ternormalisasi untuk setiap alternatif dan kriteria. Melakukan perkalian antara nilai data yang telah dinormalisasi $(N)$ dengan nilai bobot kriteria $(W)$ yang telah ditentukan. Menghitung Normalisasi Bobot $\left(F^{*}\right)$ dengan Persamaan 6 berikut ini:

$$
F_{i j}^{*}=N_{i j} \cdot W_{j}
$$

dimana, $N_{i j}$ adalah nilai data ternormalisasi untuk alternatif alternatif $i$ pada kriteria $j$, dan $W_{j}$ adalah bobot kriteria $j$.

f. Menghitung Nilai Utility Measure (S) dan Regret Measure (R) dengan Persamaan 7 dan 8 berikut ini:

$$
\begin{aligned}
S_{i} & =\sum_{j=1}^{n} F_{i j}^{*} \\
R_{i} & =\max _{j}\left\{F_{i j}^{*}\right\}
\end{aligned}
$$

dimana, $F_{i j}^{*}$ adalah nilai data ternormalisasi yang sudah terbobot untuk alternatif $i$ pada kriteria $j$, $S_{i}$ (maximum group utility) dan $R_{i}$ (minimum individual regret of the opponent), keduanya menyatakan utility measures yang diukur dari titik terjauh dan titik terdekat dari solusi ideal.

g. Menghitung indeks VIKOR $(Q)$ dengan Persamaan 9 berikut ini:

$$
Q_{i}=\left[\left(\frac{S_{i}-S^{-}}{S^{+}-S^{-}}\right)\right] v+\left[\left(\frac{R_{i}-R^{-}}{R^{+}-R^{-}}\right)\right](1-v)
$$

dimana, $S^{-}=\min \left(S_{i}\right), S^{+}=\max \left(S_{i}\right), R^{-}=\min \left(R_{i}\right), R^{+}=\max \left(R_{i}\right)$, dan $v$ merupakan bobot berkisar antara $0-1$ (umumnya bernilai 0,5 ). Semakin kecil nilai indeks VIKOR $\left(Q_{i}\right)$ maka semakin baik pula solusi alternatif tersebut.

h. Perangkingan alternatif

Perangkingan alternatif didapat setelah $Q_{i}$ dihitung, maka akan terdapat tiga macam perangkingan yaitu $S_{i}, R_{i}$, dan $Q_{i}$. Solusi kompromi dilihat pada perangkingan $Q_{i}$. Solusi kompromi ditentukan dari alternatif yang memiliki peringkat terbaik dengan mengukur indeks VIKOR yang minimum, apabila dua kondisi berikut terpenuhi.

Kondisi 1: Acceptable Advantage

dengan

$$
Q_{(\mathrm{A} 2)}-Q_{(A 1)} \geq D Q
$$

$$
D Q=\frac{1}{(m-1)}
$$

dimana $m$ adalah jumlah alternatif, alternatif $A_{1}$ adalah peringkat pertama dan $A_{2}$ adalah peringkat kedua dari perangkingan $Q_{i}$. 
Kondisi 2: Acceptable Stability in Decision Making.

Alternatif $A_{1}$ juga harus menjadi peringkat terbaik dalam perangkingan $S$ dan $R$. Solusi kompromi ini stabil dalam proses pengambilan keputusan, yang dapat menjadi: voting by majority rule (saat $v>0,5)$, atau by consensus $(v \approx 0,5)$, atau with veto $(v<0,5)$.

Jika salah satu kondisi tidak memuaskan, maka solusi kompromi dapat diajukan sebagai berikut:

1. Memilih alternatif $A_{1}$ dan $A_{2}$ jika hanya Kondisi 2 tidak memuaskan, atau

2. Memilih alternatif $A_{1}, A_{2}, \ldots, A_{m}$ jika Kondisi 1 tidak memuaskan.

$A_{m}$ merupakan alternatif yang ditentukan dengan menggunakan Persamaan 12 berikut ini:

$$
Q_{\left(\mathrm{A}_{m}\right)}-Q_{\left(A_{1}\right)}<D Q
$$

dimana $m$ maksimum adalah alternatif yang posisinya berada pada kondisi yang saling berdekatan.

\section{ANALISIS}

Metode penelitian yang digunakan dalam penelitian ini meliputi beberapa tahap yaitu pengumpulan data, analisis data, dan penarikan kesimpulan. Data yang digunakan diperoleh dari www.forlap.ristekdikti.go.id yaitu sebanyak 21 website Perguruan Tinggi Negeri yang ada di Kalimantan.

Kriteria dan bobot dalam penelitian ini diperoleh dari Webometrics, yaitu visibility (bobot 50\%), size (bobot 5\%), rich file (bobot 35\%), dan scholar (bobot 10\%). Pengumpulan data size, visibility, rich file, dan scholar dari tiap alternatif. Pengumpulan data dilakukan pada hari Jum'at tanggal 1 Februari 2019. Berikut adalah data 21 website Perguruan Tinggi Negeri di Kalimantan yang ditunjukkan pada Tabel 1.

Tabel 1. Data 21 Website Perguruan Tinggi Negeri di Kalimantan

\begin{tabular}{lrrrr}
\hline \multicolumn{1}{c}{ Perguruan Tinggi Negeri } & Size & Visibility & Rich Files & Scholar \\
\hline Politeknik Negeri Ketapang & 4.460 & 4.930 & 30 & 1 \\
Politeknik Negeri Pontianak & 14.400 & 28.200 & 151 & 184 \\
Politeknik Kesehatan Kemenkes Pontianak & 1.630 & 2.990 & 3.447 & 8 \\
Politeknik Negeri Sambas & 5.350 & 7.350 & 29 & 1 \\
Universitas Tanjungpura & 92.900 & 79.100 & 14.812 & 624 \\
Institut Agama Islam Negeri Pontianak & 4.910 & 8.900 & 179 & 2 \\
Universitas Palangka Raya & 98.100 & 67.300 & 3.373 & 49 \\
Institut Agama Islam Negeri Palangka Raya & 29.800 & 5.590 & 1.654 & 65 \\
STAKN Palangka Raya & 1.580 & 3.980 & 177 & 6 \\
Politeknik Negeri Banjarmasin & 41.000 & 19.800 & 1.161 & 35 \\
Politeknik Negeri Tanah Laut & 5.390 & 6.240 & 992 & 41 \\
Politeknik Kesehatan Kemenkes Banjarmasin & 1.600 & 2.430 & 2.566 & 4 \\
Universitas Lambung Mangkurat & 7.440 & 4.170 & 2.195 & 147 \\
Universitas Islam Negeri Antasari Banjarmasin & 60.100 & 61.600 & 2.048 & 242 \\
Institut Teknologi Kalimantan & 15.600 & 22.700 & 2.037 & 12 \\
Institut Agama Islam Negeri Samarinda & 13.000 & 6.510 & 9.019 & 56 \\
Politeknik Negeri Balikpapan & 3.450 & 4.210 & 274 & 38 \\
Politeknik Negeri Samarinda & 20.300 & 19.800 & 962 & 27 \\
Politeknik Pertanian Negeri Samarinda & 1.860 & 2.170 & 189 & 3 \\
Universitas Mulawarman & 79.800 & 98.100 & 11.564 & 1.570 \\
Universitas Borneo Tarakan & 9.140 & 10.190 & 1.863 & 62 \\
\hline
\end{tabular}




\section{PERHITUNGAN METODE VIKOR}

Setelah pengumpulan data kriteria untuk tiap alternatif selesai, selanjutnya dilakukan perangkingan alternatif dengan metode VIKOR.

1. Membuat matriks keputusan dari Tabel 1 dengan Persamaan 1 sebagai berikut:

$$
F=\left[\begin{array}{cccc}
4.460 & 4.930 & 30 & 1 \\
14.400 & 28.200 & 151 & 184 \\
1.630 & 2.990 & 3.447 & 8 \\
\vdots & \vdots & \vdots & \vdots \\
9.140 & 10.190 & 1.863 & 62
\end{array}\right]
$$

2. Menentukan bobot kriteria $(W)$

Bobot kriteria yang digunakan pada penelitian ini diambil dari Webometrics, sebagai berikut:

$$
\begin{aligned}
& \text { size }\left(W_{1}\right)=5 \%=0,05 \\
& \text { visibility }\left(W_{2}\right)=50 \%=0,5 \\
& \text { rich file }\left(W_{3}\right)=35 \%=0,35 \\
& \text { scholar }\left(W_{4}\right)=10 \%=0,1
\end{aligned}
$$

3. Menghitung nilai terbaik dan terburuk sebagai solusi ideal dengan Persamaan 3 dan 4 sebagai berikut:

$$
\begin{aligned}
f_{1}^{+} & =\max \left\{f_{11}, f_{21}, f_{31}, \ldots, f_{211}\right\} \\
& =\max \{4.460,14.400,1.630, \ldots, 9.140\} \\
& =98.100 \\
f_{1}^{-} & =\min \left\{f_{11}, f_{21}, f_{31}, \ldots, f_{211}\right\} \\
& =\min \{4.460,14.400,1.630, \ldots, 9.140\} \\
& =1.580 \\
f_{2}^{+} & =\max \left\{f_{12}, f_{22}, f_{32}, \ldots, f_{212}\right\} \\
& =\max \{4.930,28.200,2.990, \ldots, 10.190\} \\
& =99.300 \\
f_{2}^{-} & =\min \left\{f_{12}, f_{22}, f_{32}, \ldots, f_{212}\right\} \\
& =\min \{4.930,28.200,2.990, \ldots, 10.190\} \\
& =2.170
\end{aligned}
$$

dan seterusnya sampai $f_{4}^{+}$dan $f_{4}^{-}$. Perhitungan solusi ideal disajikan dalam Tabel 2 sebagai berikut:

Tabel 2. Nilai Solusi Ideal

\begin{tabular}{|c|cccc|}
\hline & $C_{1}$ & $C_{2}$ & $C_{3}$ & $C_{4}$ \\
\hline$f_{j}^{+}$ & 98.100 & 99.300 & 14.812 & 1.570 \\
$f_{j}^{-}$ & 1.580 & 2.170 & 29 & 1 \\
\hline
\end{tabular}


4. Membuat matriks normalisasi $(N)$ dengan menggunakan Persamaan 5 sebagai berikut:

$$
\begin{gathered}
N_{11}=\frac{f_{1}^{+}-f_{11}}{f_{1}^{+}-f_{1}^{-}}=\frac{98.100-4.460}{98.100-1.580}=0,970 \\
N_{12}=\frac{f_{2}^{+}-f_{12}}{f_{2}^{+}-f_{2}^{-}}=\frac{99.300-4.930}{99.300-2.170}=0,972 \\
N_{13}=\frac{f_{3}^{+}-f_{13}}{f_{3}^{+}-f_{3}^{-}}=\frac{14.812-30}{14.812-29}=0,999 \\
N_{14}=\frac{f_{4}^{+}-f_{14}}{f_{4}^{+}-f_{4}^{-}}=\frac{1.570-1}{1.570-1}=1,000
\end{gathered}
$$

dan seterusnya sampai $N_{214}$ sehingga diperoleh matriks normalisasi $N$ sebagai berikut:

$$
N=\left[\begin{array}{cccc}
0,970 & 0,972 & 0,999 & 1,000 \\
0,867 & 0,732 & 0,992 & 0,883 \\
0,999 & 0,992 & 0,769 & 0,996 \\
\vdots & \vdots & \vdots & \vdots \\
0,922 & 0,917 & 0,876 & 0,961
\end{array}\right]
$$

5. Menghitung normalisasi bobot $\left(F^{*}\right)$ dengan menggunakan Persamaan 6 sebagai berikut:

$$
\begin{gathered}
F_{11}^{*}=N_{11} \cdot W_{1}=0,970 \cdot 0,05=0,049 \\
F_{12}^{*}=N_{12} \cdot W_{2}=0,972 \cdot 0,5=0,486 \\
F_{13}^{*}=N_{13} \cdot W_{3}=1,000 \cdot 0,35=0,350 \\
F_{14}^{*}=N_{14} \cdot W_{4}=1,000 \cdot 0,1=0,100
\end{gathered}
$$

dan seterusnya sampai $F_{214}$ sehingga diperoleh matriks $F^{*}$ sebagai berikut:

$$
F^{*}=\left[\begin{array}{cccc}
0,049 & 0,486 & 0,350 & 0,100 \\
0,043 & 0,366 & 0,347 & 0,088 \\
0,050 & 0,496 & 0,269 & 0,100 \\
\vdots & \vdots & \vdots & \vdots \\
0,046 & 0,459 & 0,307 & 0,096
\end{array}\right]
$$

6. Menghitung utility measure $(S)$ dan regret measure $(R)$ dengan menggunakan Persamaan 7 dan 8 sebagai berikut:

dan seterusnya sampai $S_{21}$.

$$
\begin{aligned}
& S_{1}=\sum_{j=1}^{4} F_{1 j}^{*}=0,049+0,486+0,350+0,100=0,984 \\
& S_{2}=\sum_{j=1}^{4} F_{2 j}^{*}=0,043+0,366+0,347+0,088=0,843
\end{aligned}
$$

$$
\begin{aligned}
& R_{1}=\max \left\{F_{1 j}^{*}\right\}=\max \{0,049 \quad 0,486 \quad 0,350 \quad 0,100\}=0,486 \\
& R_{1}=\max \left\{F_{1 j}^{*}\right\}=\max \{0,043 \quad 0,366 \quad 0,347 \quad 0,088\}=0,366
\end{aligned}
$$

dan seterusnya sampai $R_{21}$. 
Perhitungan nilai $S_{i}$ dan $R_{i}$ disajikan pada Tabel 3 berikut:

Tabel 3. Nilai $S_{i}$ dan $R_{i}$

\begin{tabular}{lrr}
\hline \multicolumn{1}{c}{ Perguruan Tinggi Negeri } & $S_{i}$ & $R_{i}$ \\
\hline Politeknik Negeri Ketapang & 0,984 & 0,486 \\
Politeknik Negeri Pontianak & 0,843 & 0,364 \\
Politeknik Kesehatan Kemenkes Pontianak & 0,914 & 0,496 \\
Politeknik Negeri Sambas & 0,971 & 0,473 \\
Universitas Tanjungpura & 0,162 & 0,099 \\
Institut Agama Islam Negeri Pontianak & 0,960 & 0,465 \\
Universitas Palangka Raya & 0,528 & 0,271 \\
Institut Agama Islam Negeri Palangka Raya & 0,925 & 0,482 \\
STAKN Palangka Raya & 0,987 & 0,491 \\
Politeknik Negeri Banjarmasin & 0,859 & 0,408 \\
Politeknik Negeri Tanah Laut & 0,951 & 0,479 \\
Politeknik Kesehatan Kemenkes Banjarmasin & 0,938 & 0,499 \\
Universitas Lambung Mangkurat & 0,926 & 0,490 \\
Universitas Islam Negeri Antasari & 0,597 & 0,302 \\
Institut Teknologi Kalimantan & 0,837 & 0,393 \\
Institut Agama Islam Negeri Samarinda & 0,755 & 0,477 \\
Politeknik Negeri Balikpapan & 0,980 & 0,489 \\
Politeknik Negeri Samarinda & 0,875 & 0,408 \\
Politeknik Pertanian Negeri Samarinda & 0,996 & 0,500 \\
Universitas Mulawarman & 0,086 & 0,077 \\
Universitas Borneo Tarakan & 0,907 & 0,458 \\
\hline
\end{tabular}

Berdasarkan Tabel 3 didapatkan bahwa $S^{-}=0,086$ (Universitas Mulawarman), $S^{+}=0,996$ (Politeknik Pertanian Negeri Samarinda), $R^{-}=0,077$ (Universitas Mulawarman), dan $R^{+}=$ 0,500 (Politeknik Pertanian Negeri Samarinda).

7. Menghitung indeks VIKOR $(Q)$

Pada perhitungan indeks VIKOR ini digunakan nilai voting by majority rule yaitu $v=0,5$ sebagai berikut:

$$
\begin{aligned}
& Q_{1}=\left[\left(\frac{0,984-0,086}{0,996-0,086}\right)\right] 0,5+\left[\left(\frac{0,486-0,077}{0,500-0,077}\right)\right](1-0,5)=0,977 \\
& Q_{2}=\left[\left(\frac{0,843-0,086}{0,996-0,086}\right)\right] 0,5+\left[\left(\frac{0,364-0,077}{0,500-0,077}\right)\right](1-0,5)=0,759 \\
& Q_{3}=\left[\left(\frac{0,914-0,086}{0,996-0,086}\right)\right] 0,5+\left[\left(\frac{0,496-0,077}{0,500-0,077}\right)\right](1-0,5)=0,950
\end{aligned}
$$

dan seterusnya sampai $Q_{21}$. 
Perhitungan nilai $Q_{i}$ disajikan pada Tabel 4 berikut:

Tabel 4. Hasil Pencarian Nilai $Q_{i}$

\begin{tabular}{lc}
\hline \multicolumn{1}{c}{ Perguruan Tinggi Negeri } & $Q_{i}$ \\
\hline Politeknik Negeri Ketapang & 0,977 \\
Politeknik Negeri Pontianak & 0,759 \\
Politeknik Kesehatan Kemenkes Pontianak & 0,950 \\
Politeknik Negeri Sambas & 0,955 \\
Universitas Tanjungpura & 0,076 \\
Institut Agama Islam Negeri Pontianak & 0.939 \\
Universitas Palangka Raya & 0,474 \\
Institut Agama Islam Negeri Palangka Raya & 0,940 \\
STAKN Palangka Raya & 0,984 \\
Politeknik Negeri Banjarmasin & 0,818 \\
Politeknik Negeri Tanah Laut & 0,951 \\
Politeknik Kesehatan Kemenkes Banjarmasin & 0,967 \\
Universitas Lambung Mangkurat & 0,949 \\
Universitas Islam Negeri Antasari & 0,549 \\
Institut Teknologi Kalimantan & 0,789 \\
Institut Agama Islam Negeri Samarinda & 0,841 \\
Politeknik Negeri Balikpapan & 0,979 \\
Politeknik Negeri Samarinda & 0,821 \\
Politeknik Pertanian Negeri Samarinda & 1,000 \\
Universitas Mulawarman & 0,000 \\
Universitas Borneo Tarakan & 0,903 \\
\hline
\end{tabular}

8. Perangkingan alternatif

Perangkingan alternatif dengan cara mengurutkan mulai dari nilai $Q_{i}$ terkecil hingga terbesar. Hasil perangkingan 21 website Perguruan Tinggi Negeri di Kalimantan dengan menggunakan metode VIKOR disajikan pada Tabel 5 sebagai berikut:

Tabel 5. Perangkingan Metode VIKOR

\begin{tabular}{lc}
\hline \multicolumn{1}{c}{ Perguruan Tinggi } & $Q_{i}$ \\
\hline Universitas Mulawarman & 0,000 \\
Universitas Tanjungpura & 0,076 \\
Universitas Palangka Raya & 0,474 \\
Universitas Islam Negeri Antasari & 0,549 \\
Politeknik Negeri Pontianak & 0,759 \\
Institut Teknologi Kalimantan & 0,789 \\
Politeknik Negeri Banjarmasin & 0,818 \\
Politeknik Negeri Samarinda & 0,827 \\
Institut Agama Islam Negeri Samarinda & 0,841 \\
Universitas Borneo Tarakan & 0,903 \\
Institut Agama Islam Negeri Pontianak & 0,939 \\
Institut Agama Islam Negeri Palangka Raya & 0,940 \\
\hline
\end{tabular}


Tabel 5. Perangkingan Metode VIKOR (lanjutan)

\begin{tabular}{lc}
\hline \multicolumn{1}{c}{ Perguruan Tinggi } & $Q_{i}$ \\
\hline Universitas Lambung Mangkurat & 0,949 \\
Politeknik Kesehatan Kemenkes Pontianak & 0,950 \\
Politeknik Negeri Tanah Laut & 0,951 \\
Politeknik Negeri Sambas & 0,955 \\
Politeknik Kesehatan Kemenkes Banjarmasin & 0,967 \\
Politeknik Negeri Ketapang & 0,977 \\
Politeknik Negeri Balikpapan & 0,979 \\
STAKN Palangka Raya & 0,984 \\
Politeknik Pertanian Negeri Samarinda & 1,000 \\
\hline
\end{tabular}

Berdasarkan Tabel 5 diketahui bahwa peringkat website Perguruan Tinggi Negeri terbaik di Kalimantan dengan menggunakan metode VIKOR ditempati oleh Universitas Mulawarman dengan indeks sebesar 0,000. Universitas Tanjungpura ditempat kedua dengan indeksVIKOR sebesar 0,076. Sedangkan peringkat ketiga dengan indeks VIKOR sebesar 0,474 ditempati oleh Universitas Palangka Raya.

Solusi kompromi ditentukan dari alternatif yang memiliki peringkat terbaik dengan mengukur indeks VIKOR yang minimum, apabila dua kondisi berikut terpenuhi:

Kondisi 1: Acceptable Advantage

Pembuktian Kondisi 1 dengan menggunakan Persamaan 10 dan 11 sebagai berikut:

dengan

$$
Q_{(\mathrm{A} 2)}-Q_{(A 1)}=0,076-0=0,076
$$

$$
D Q=\frac{1}{(21-1)}=0,05
$$

Karena nilai $Q_{(\mathrm{A} 2)}-Q_{(A 1)} \geq D Q$ yaitu $0,076>0,05$ maka dapat dikatakan bahwa Kondisi 1 terpenuhi.

\section{Kondisi 2: Acceptable Stability in Decision Making}

Hasil peringkat terbaik dari perankingan dengan $v=0,5$ adalah Universitas Mulawarman yang sama dengan peringkat terbaik dari perankingan $Q$. Hasil perangkingan pada $S$ dan $R$ juga didapat bahwa peringkat terbaik adalah Universitas Mulawarman dengan nilai $S=0,086$ dan $S=0,077$. Berdasarkan hasil yang diperoleh dapat dibuktikan bahwa Kondisi 2 terpenuhi.

\section{KESIMPULAN}

Berdasarkan hasil penelitian dan pembahasan maka ditarik kesimpulan bahwa penggunaan metode VIKOR dapat membantu proses perangkingan website Perguruan Tinggi Negeri di Kalimantan. Berdasarkan hasil perangkingan didapat bahwa Universitas Mulawarman merupakan Perguruan Tinggi Negeri dengan website terbaik di Kalimantan. Peringkat kedua didapat Universitas Tanjungpura, disusul peringkat ketiga dengan Universitas Palangka Raya.

\section{DAFTAR PUSTAKA}

[1]. Kahraman, C. Fuzzy Multi-Criteria Decision Making: Theory And Applications With Recent Developments, Springer Verlag. 2008. 
[2]. Kristyawan, Y. dan Rizeki, A. Sistem Pendukung Keputusan Distribusi Rehabilitas Sosial Rumah Tidak Layak Huni pada Kab. Sampang Menggunakan Metode VIKOR. Jurnal INFORM. 2017. 2(1):1-8.

[3]. Kusumadewi, S. Fuzzy Multi-Attribute Decision Making. Yogyakarta: Graha Ilmu. 2006.

[4]. Siregar, A.; Ginting, P.; Mesran dan Sianturi L. T. Implementasi Metode VIKOR dalam Pemilihan Supplier Bahan Baku. KOMIK. 2017. 1(1):132-138.

[5]. Suwardika, G. dan Suniantara, I. K. P. Penerapan Metode VIKOR pada Pengambilan Keputusan Seleksi Calon Penerima Beasiswa Bidikmisi Universitas Terbuka. Jurnal INTENSIF. 2018. 2(1):24-3.

$\begin{array}{lll}\text { MALIK ABDUL RASYID } & : & \begin{array}{l}\text { Jurusan Matematika FMIPA Untan, Pontianak, } \\ \text { malik_mars@ @ocketmail.com }\end{array} \\ \text { EVY SULISTIANINGSIH } & : & \begin{array}{l}\text { Jurusan Matematika FMIPA Untan, Pontianak, } \\ \text { evysulistianingisih@math.untan.ac.id }\end{array} \\ \text { NURFITRI IMRO’AH } & : & \begin{array}{l}\text { Jurusan Matematika FMIPA Untan, Pontianak, } \\ \text { nurfitriimroah@math.untan.ac.id }\end{array}\end{array}$

